Indexed by

\title{
INVESTIGATION OF THE METHOD OF PROCESSING HOLES WITH A ROTARY CUP CUTTER WITH SURFACING
}

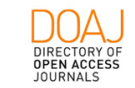

Crossref

\section{Bakytzhan Donenbayev}

Karaganda Technical University, Mechanical Engineering faculty, Karaganda, Kazakhstan

\section{Medgat Mussayev \\ Karaganda Technical Univer- sity, Mechanical Engineering faculty, Karaganda, Kazakh- stan}

\author{
Karibek Sherov \\ Karaganda Technical \\ University, Mechanical Engi- \\ neering faculty, Karaganda, \\ Kazakhstan
}

\author{
Assylkhan Mazdubay \\ Toraigyrov University, \\ Mechanical Engineering facul- \\ ty, Pavlodar, Kazakhstan
}

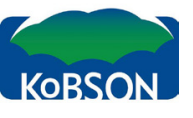

zakhstan

\section{Saule Ainabekova}

Karaganda Technical University, Mechanical Engineering faculty, Karaganda, Kazakhstan

\author{
Aizhan Taskarina \\ Toraigyrov University, Me- \\ chanical Engineering faculty, \\ Pavlodar, Kazakhstan
}

\author{
Riza Gabdyssalyk \\ D. Serikbayev East Kazakh- \\ stan University, Department \\ of mechanical engineering, \\ Ust-Kamenogorsk, \\ Kazakhstan
}

\section{Sayagul Tussupova Toraigyrov University, Me- chanical Engineering faculty, Pavlodar, Kazakhstan}

Key words: generalized Zhurkov equation, errors, durability prediction, thermal fluctuation concept, economic efficiency

doi:10.5937/jaes0-27504

Cite article:

Donenbayev B., Sherov K., Mazdubay A., Sherov A., Mussayev M., Gabdyssalyk R., Ainabekova S., Taskarina A., Tussupova S.

(2021) INVESTIGATION OF THE METHOD OF PROCESSING HOLES WITH A ROTARY CUP CUTTER WITH SURFACING, Journal of Applied Engineering Science, 19(4), 862 867, DOI:10.5937/ jaes0-27504

Online aceess of full paper is available at: www.engineeringscience.rs/browse-issues 


\title{
INVESTIGATION OF THE METHOD OF PROCESSING HOLES WITH A ROTARY CUP CUTTER WITH SURFACING
}

\author{
Bakytzhan Donenbayev', Karibek Sherov ${ }^{1 *}$, Assylkhan Mazdubay ${ }^{2}$, Aybek Sherov ${ }^{3}$, Medgat Mussayev', \\ Riza Gabdyssalyk ${ }^{4}$, Saule Ainabekova', Aizhan Taskarina'2, Sayagul Tussupova² \\ ${ }^{1}$ Karaganda Technical University, Mechanical Engineering faculty, Karaganda, Kazakhstan \\ ${ }^{2}$ Toraigyrov University, Mechanical Engineering faculty, Pavlodar, Kazakhstan \\ ${ }^{3}$ LIP «Kazakhstan Aviation Industry», Nur-Sultan, Kazakhstan \\ ${ }^{4}$ D. Serikbayev East Kazakhstan University, Department of mechanical engineering, Ust-Kamenogorsk, \\ Kazakhstan
}

This article presents the experimental study results of the process of rotational friction holes boring using a cup cutter surfaced by STOODY M7-G material. As a result of experimental studies, the following quality indicators were achieved: surface roughness within $R_{a}=10 \div 1,25$ micrometer; surface hardness within HB 212-248. Using a cup cutter surfaced by STOODY M7-G material in case of rotational friction boring of large-diameter holes for large-sized parts can improve processing performance in comparison with cutting tools equipped with hard metal plates and provided the required surface roughness. Preliminary calculations showed that the manufacture of cup cutters from non-instrumental materials reduces the cost of the cutting tool by 5-7 times and the cost of the operation by 1.5-2 times.

Key words: A cup cutter, surfaced, rotational-friction boring, large-sized parts, large hole, roughness

\section{INTRODUCTION}

One of the essential issues of modern mechanical engineering is a creation of progressive tool designs and advanced technologies for metal cutting. [1] The dominant role of the machining processes in the technological cycle of most important parts, in particular large-sized parts, is mainly due to its versatility, efficiency and high accuracy. At the same time, the traditional methods of mechanical processing, which have now become widespread, do not always meet the ever-increasing demands in productivity and quality. This is especially noticeable in heavy engineering conditions, when machining large-sized openings of large-sized parts. The task of increasing production efficiency cannot be solved without using the most advanced technologies that meet the following set of requirements [1]: universality, i.e. the possibility of applying to various technological operations and for various materials of the workpieces; energy efficiency in terms of energy consumption; high processing performance; simple and cheap construction of tools at low cost; simple kinematics and the possibility of implementation on a fairly simple, including universal, equipment; wastelessness and environmental friendliness. The rotational-friction processing technology fully meets the requirements. As well as the use of rotational-friction boring (RFB) holes reduces the transitions of the boring operation, ensuring the quality of the corresponding fine boring. The results of the research carried out in the conditions of machine-building plants of the Republic of Kazakhstan, in particular, Karaganda region showed that more than $40 \%$ of the parts subjected to machining, have holes machined by the boring operation. When ma- chining large-sized holes of large parts, when the boring length exceeds the maximum spindle or table stroke, a differential boring bar is used. When working with differential boring bars, additional errors appear due to the gap between the boring bar and the moving coupling, on which the boring head is attached. The choice of delivering and cutting speed when processing holes of large sizes of large parts is carried out in accordance with the principles. When finishing, the selected cutting mode must ensure compliance with the specified accuracy and surface roughness without stopping the machine and adjusting the tool size. When machining large sizes, the choice of this cutting mode is of particular importance. When machining parts on boring machines and especially when machining openings of large sizes of largesized parts, the auxiliary time considerably exceeds the machine time. Therefore, the issue of increasing labor productivity should first be sought in reducing the auxiliary time. The high performance of the combined rotary-friction tools for combined processing is provided by a sharp reduction in machine and auxiliary processing time, as well as tempo related to the installation and setup of tools on the machine for performing individual operations. The "Technological equipment, mechanical engineering and standardization" department of Karaganda State Technical University has developed methods for thermal friction processing at low speeds $[2,3,4]$. On the basis of the cutting mechanism of these methods in the framework of the implementation of the grant theme No. 2162 / GF4 (Reg. No. 0215PK02401), a method of RFB holes was developed $[5,6,7]$.

The developed combined tools for rotational-friction 
cutting are created by combining two methods of thermo-friction and rotational processing, working on the basis of a single kinematics - free rotation in the processing of cutting elements. They have a number of advantages in comparison with the tools created for traditional rotary processing, namely, high durability, productivity and ease of sharpening the cutting element.

In this regard, studies of the machinability of large-sized holes of parts made of $30 \mathrm{HGSA}$ steel using the RDB method using rotary-friction tools equipped with a cup cutter with surfaced STOODY M7-G material is an important task.

\section{METHODS AND EQUIPMENT FOR THE STUDY}

The tasks set in the work were solved by an experimental method. The experimental study of the rotational-friction boring of holes using a cup cutter surfaced by STOODY M7-G material was carried out on a 1M63BF101 turning screw cutter in the conditions of JSC Almaty Heavy Machine Building Plant. 16 experiments were carried out. Billet part "glass" of the pumping unit was used for processing in the experimental study. Material of the details is steel 30HGSA. The size of the machined hole: $\varnothing 305$ $\mathrm{mm}, \mathrm{L}=56 \mathrm{~mm}$. Experimental studies of the angle effect of the tool installation on the quality indicators for the RDB holes when machining a part from steel 30HGSA were performed on a lathe using a rotary friction tool equipped with a cup cutter surfaced by STOODY M7-G material.

Surfacing material STOODY M7-G is characterized by high hardness (from 58 to $66 \mathrm{HRC}$ ) and excellent wear resistance [8]. It can be used at elevated temperatures up to $1000 \mathrm{~F}\left(537.78^{\circ} \mathrm{C}\right)$, under conditions of moderate thermal shock. Table 1 shows the chemical composition and hardness of the material.

Figure 1 shows a tool equipped with a cup cutter surfaced STOODY M7-G material.

Table 1: Chemical composition and hardness of the surfaced STOODY M7-G material, \%

\begin{tabular}{|c|c|c|c|c|c|c|c|}
\hline $\mathrm{C}$ & $\mathrm{Cr}$ & $\mathrm{Mn}$ & $\mathrm{Mo}$ & $\mathrm{V}$ & $\mathrm{W}$ & $\mathrm{Fe}$ & hardness \\
\hline 1,0 & 4,0 & 0,4 & 9,0 & 2,0 & 2,0 & The rest & $\begin{array}{c}58-66 \\
\text { HRC }\end{array}$ \\
\hline
\end{tabular}

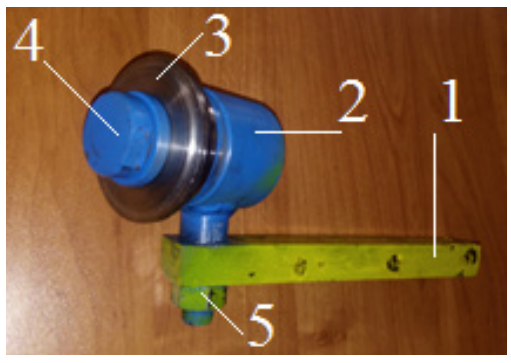

(a)

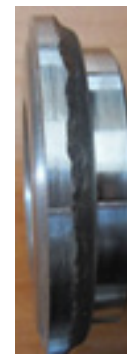

(b) a - tool assembly; $b$ - cup cutter; 1 - holder; 2 - bearing housing; 3 - cup cutter; 4,5 - a nut for a clip

Figure 1: A tool equipped with a cup cutter surfaced STOODY M7-G material
Measurements of roughness and hardness were carried out in the technical control department of the research laboratories of the plant.

\section{PLANNING AN EXPERIMENT TO INVESTIGATE QUALITY INDICATORS}

To obtain the dependences of quality indicators during rotational-friction boring of the inner surface of large-sized orifices, a planned experiment was carried out. The quality indicators in one degree or another are influenced by a large number of factors of the technological process. According to preliminary experiments and analysis of the literature, three main variable factors were selected, which responded to surface quality indicators: $X_{1}$ is spindle speed, rpm $(n) ; \mathrm{X}_{2}$ is feed rotary tool, $\mathrm{mm} / \mathrm{rev}(S) ; \mathrm{X}_{3}$ is the angle of installation of the cutting cup, degree $(\beta)$.

According to the method described in $[9,10]$, a combined square was constructed for a three-factor complex. The ranges of variation of the factors were chosen according to the literature and preliminary experiments in such a way that monotonic changes in the studied parameters of the surface quality of the coating were obtained within these limits. The plan of the three-factor experiment at four levels is given in table 2 .

The method of rational planning of experiments reduces the number of necessary experiments by $\mathrm{n}^{\mathrm{m}-1}$ compared with a full experiment. For our case, when $n=4, m=3$, the number of experiments using rational planning is reduced by 4 times and becomes equal to 16 .

The structure of the plan guarantees the statistical equivalence of the sample of results for each level of each factor.

Table 2: Plan three-factor experiment

\begin{tabular}{|c|c|c|c|c|c|}
\hline Factors & $X_{1}$ & $X_{2}$ & $X_{3}$ & $Y_{1}$ & $Y_{2}$ \\
\hline 1 & 265 & 0,07 & 10 & 9,5 & 320 \\
\hline 2 & 265 & 0,9 & 25 & 7,6 & 260 \\
\hline 3 & 265 & 0,31 & 35 & 8,8 & 300 \\
\hline 4 & 265 & 0,45 & 7 & 8,1 & 265 \\
\hline 5 & 500 & 0,07 & 25 & 8,7 & 305 \\
\hline 6 & 500 & 0,9 & 35 & 6,2 & 245 \\
\hline 7 & 500 & 0,31 & 7 & 7,6 & 290 \\
\hline 8 & 500 & 0,45 & 10 & 6,5 & 270 \\
\hline 9 & 875 & 0,07 & 35 & 7,5 & 275 \\
\hline 10 & 875 & 0,9 & 7 & 3,4 & 225 \\
\hline 11 & 875 & 0,31 & 10 & 6,6 & 270 \\
\hline 12 & 875 & 0,45 & 25 & 6,0 & 254 \\
\hline 13 & 1250 & 0,07 & 7 & 6,5 & 252 \\
\hline 14 & 1250 & 0,9 & 10 & 1,2 & 220 \\
\hline 15 & 1250 & 0,31 & 35 & 4,2 & 238 \\
\hline 16 & 1250 & 0,45 & 25 & 2,8 & 230 \\
\hline
\end{tabular}


Note

The following quality indicators were investigated: $Y_{1}$ - roughness of the processed surface $R_{a}, \mu m$; $\mathrm{Y}_{2}$ - hardness of the processed surface $\mathrm{HB}, \mathrm{kgf} / \mathrm{mm}^{2}$.

The experiments were carried out on the workpiece parts "glass", made of steel 30HGSA.

\section{EXPERIMENTAL RESEARCH AND DISCUSSION OF THE RESULTS}

Processing is made with a cup cutter, surfaced by STOODY M7-G material. Boring modes varied in the following limits: $n_{s r}=10 \div 1250 \mathrm{rpm} ; \beta=7^{\circ} \div 35^{\circ} ; S=0,07 \div 1,3$ $\mathrm{mm} / \mathrm{rev} ; t=1 \div 3 \mathrm{~mm}$. The speed of rotation of the tool is determined from the following dependencies:

with single pass boring

$$
n_{\text {cutt }}=\frac{\left(D_{\text {bil }}+2 t\right)}{D_{\text {cutt }}} \cdot n_{\text {sp }} \cdot \cos \beta
$$

with multipass boring from one installation

$$
n_{\text {cutt }}=\frac{\left(D_{\text {bil }}+2 n \cdot t\right)}{D_{\text {cutt }}} \cdot n_{s p} \cdot \cos \beta
$$

where,

$D_{\text {bil }}$ - is the diameter of the billet (workpiece); $D_{\text {cutt }}-$ is diameter of the cup cutter; $n_{s p}$ - is spindle rotational speed; $n$ - is the number of passes; $t$ - allowance; $\beta$ - the installation angle of the tool.

Figure 2 shows the process of rotational friction boring of the workpiece holes of the "glass" part.

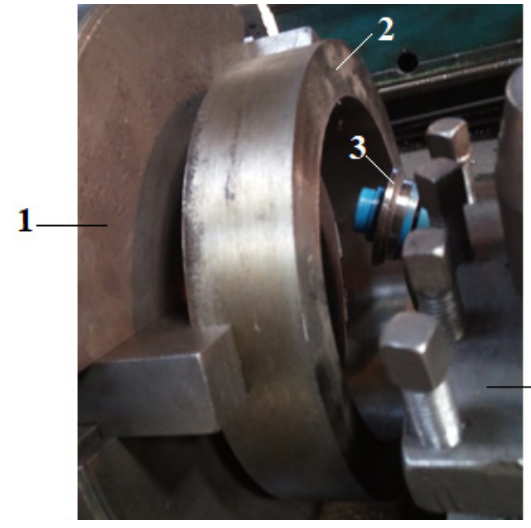

(a)

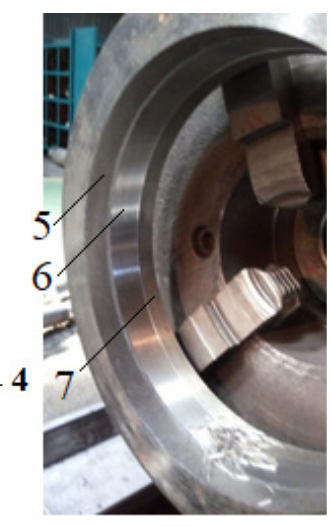

(b) a - processing; $b$ - processed surfaces with different cutting conditions; 1 - three-jaw chuck; 2 - detail "glass"; 3 - a cup cutter surfaced by STOODY M7-G material; 4 tool holder; 5 - $t=1 \mathrm{~mm} ; \beta=10^{\circ} ; S=0,26 \mathrm{~mm} / \mathrm{rev} ; n_{s r}=500$ rpm; 6 - $t=1 \mathrm{~mm} ; \beta=10^{\circ} ; S=0,7 \mathrm{~mm} / \mathrm{rev} ; n_{\mathrm{sr}}=875 \mathrm{rpm}$;

$7-t=1 \mathrm{~mm} ; \beta=10^{\circ} ; S=1,3 \mathrm{~mm} / \mathrm{rev} ; n_{\mathrm{sr}}=1250 \mathrm{rpm}$

Figure 2: Rotational friction boring holes

The results of theoretical and experimental studies convincingly show that the performance properties of the mining equipment parts are significant, and in most cases, decisively affected by the quality parameters of their working surfaces. In order to ensure one or another op- erational property of the part or unit being manufactured, it is necessary to ensure the required, defining its characteristics, the quality of working surfaces. To solve this problem, you should know the dependencies that associate the characteristics of the quality of the surface being treated with the processing conditions (modes, tool geometry, etc.), and the dependencies should reflect the influence of technological heredity. This is due to the fact that the quality characteristics of the processed surfaces, according to the studies of many scientists $[11,12,13]$, are formed throughout the entire process of manufacturing parts, and not only at the finishing operations $[14,15]$. It should be noted that quantitative relationships between quality parameters and processing conditions can be obtained in two ways: through in-depth studies of physical phenomena occurring in the surface layer during processing, and through specially designed statistical studies. Statistical studies require much less time and resources and allow you to get results in the form of appropriate statistical models that are simple in practical use and fairly accurately reflect the quantitative side of the process under consideration. The processing of the results of a multifactor experiment was carried out according to the program "ANETR-5", developed in [10]. The method is universal, both in terms of the scope of application and in variants of model building: models can have the form of a sum, the product of private dependencies, their combinations, with and without successive neutralization of the effect of the priority arguments. An important advantage of the method is the ability to adequately assess the impact of those arguments that will be excluded from the analysis in traditional methods, as they do not significantly affect the objective function (for example, by the Fisher's criterion). The method is determined, i.e. allows you to limit the choice of the model of known data on the theory of the process (type of equation, limits, etc.). At the output, the program, in addition to the analytical nature of private communications, provides their graphs, an assessment of reliability, ranks the factors according to the strength of the interaction on the result, and makes it possible to identify significantly influencing factors. The degree of adequacy of the models found to the source data is estimated through the standard deviation (SD).

$$
S D \%=100 \sqrt{\frac{\sum\left(Y_{e}-Y_{c}\right)^{2}}{N-1}} / \sqrt{\frac{\sum\left(Y_{e}-\bar{Y}_{a}\right)^{2}}{N-1}}
$$

where,

$Y_{e}$ is the experimental value of the function (coating quality parameter); $Y_{c}$ is the calculated value of the function; $\bar{Y}_{a}$ - is the average value of the function; $N$ is the number of experiments.

Besides SD, between the original data and the calculated ones, the multiple correlation coefficient $R$ and the Fisher's criterion F were calculated.

According to the reference [16], the model is considered to be excellent if SD is less than $20 \%$ and good, if SD is 
in the range from $20 \%$ to $50 \%$.

As a result of data processing, the following dependencies were obtained:

1) $Y_{1}$ - surface roughness $R_{a}$, micrometer

$$
\begin{aligned}
& Y_{1}=\left(1 /\left(8,80084 \cdot 10^{-2}+2,71133 \cdot 10^{-4} X_{1}\right)\right)+ \\
& \quad+\left(1,70656 \cdot 10^{-1} / X_{2}\right)+4,8352 \cdot\left(e^{8,02792 \cdot 10^{-3} \cdot X_{3}}\right) ; \\
& -S D=49 \%, R=0,837 .
\end{aligned}
$$

The calculated Fisher's criterion $F=3.76381$ is obtained less than for $1 \%$ level of significance $F(001)=3.52418$ and for $5 \%$ level of significance $F(005)=2.38818$;

2) $Y_{2}$ - the hardness of the treated surface $H B, \mathrm{kgf} / \mathrm{mm}^{2}$

$$
\begin{aligned}
& Y_{2}=1,81 \cdot 10^{3} \cdot X_{1}^{-0,383}+\left(1 /\left(7,46 \cdot 10^{-3}-8,11 \cdot 10^{-3} \cdot X_{2}\right)\right)- \\
& \quad-\left(156,86 / X_{2}\right)-189,29 ; \\
& -S D=34,63 \%, R=0,922 . \\
& F=8,33772 ; F(001)=3,52418 ; F(005)=2,38818 ;
\end{aligned}
$$

The received mathematical model linking the spindle speed ( $\mathrm{n}$ ), delivering (S) and tool setting angle allows you to control the quality parameters of the surface of a large-bore hole and determine the optimal processing conditions that provide high machining accuracy. Using a cup cutter surfaced by STOODY M7-G material with rotational friction boring of large-diameter holes for largesized parts can improve processing performance in comparison with cutting tools equipped with hard metal plates and provide the required surface roughness.

Figure 3 shows the graphs of the roughness and surface hardness as a function of the rotational speed and installation angle of the tool, with a cup cutter surfaced by STOODY M7-G material.

As a result of the study of the influence of the spindle speed and delivering on the quality indicators, it was found that an increase in the spindle speed and delivering favorably affects the roughness and hardness on the machined surface (see Figure $3 a, b$, straight 5 ). At the maximum spindle speeds and delivering, the high quality of the machined surface was ensured: surface roughness $R_{\mathrm{a}} \leq 1 \mu \mathrm{m}$ (see Figure 3a straight 5); surface hardness HB2 $12 \div 248$ for steel $30 \mathrm{HGSA}$ (see Figure $3 b$ straight 5).

However, the favorable effect of an increase in delivering on the quality of the processed surface contradicts the hypothesis about the cutting mechanism of rotational-friction cutting. It can be explained by the fact that the surfaced STOODY M7-G material used for surfacing the periphery of the cup tool has hardness RRC58-66 [8]. So it can be assumed that the cutting mechanism in processing this plate cutter corresponds to the mechanism of traditional cutting or close to it. Refining this process requires additional research. As a result of the analysis and processing of the obtained data, the following optimal cutting conditions were determined for the processing of 30HGSA steel with a tool equipped with a cutting tool surfaced by STOODY M7-G material $S=1.3 \mathrm{~mm} /$ rev; $n_{\text {srs }}=1250 \mathrm{rpm} ; t=1 \mathrm{~mm}$.

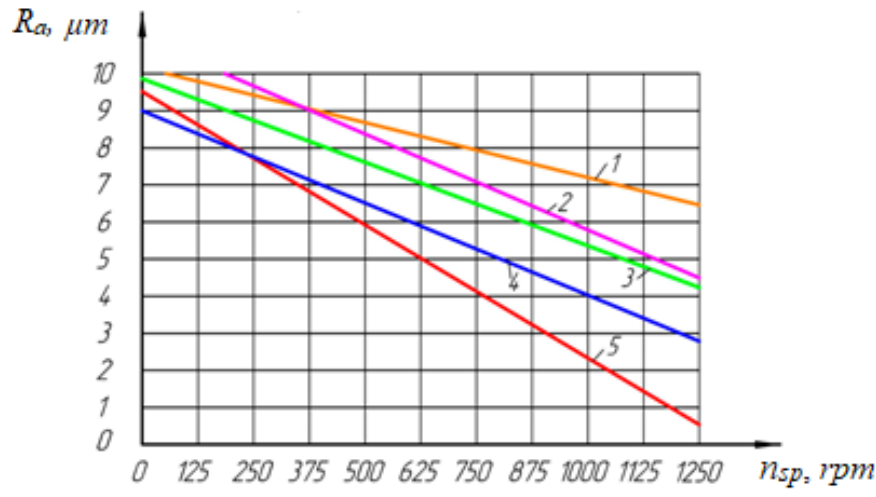

(a)

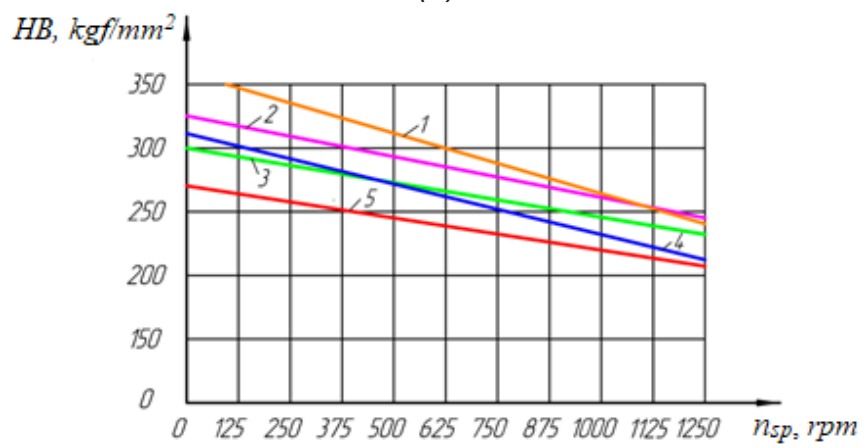

(b)

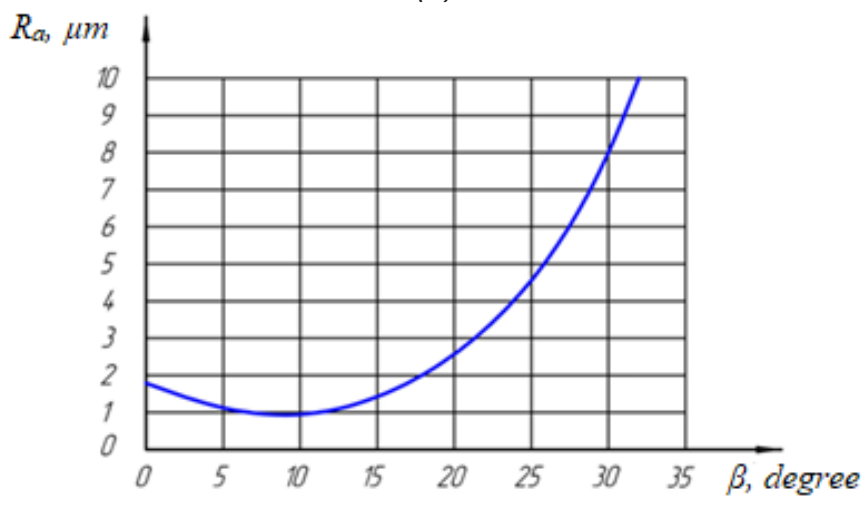

(c)

a - graphs of the dependence of the surface roughness on spindle speed; $b$ - graphs of the dependence of the surface hardness on the spindle speed; c - graphs of the dependence of the surface roughness on the tool installation angle; $t=1 \mathrm{~mm} ; \beta=10^{\circ} ; 1-S=0.07 \mathrm{~mm} /$ $\mathrm{rev} ; 2-S=0.26 \mathrm{~mm} / \mathrm{rev} ; 3-S=0.4 \mathrm{~mm} / \mathrm{rev} ; 4-\mathrm{S}=0.7$ $\mathrm{mm} / \mathrm{rev} ; 5-\mathrm{S}=1.3 \mathrm{~mm} / \mathrm{rev}$

Figure 3: Graphs of the dependence of roughness and surface hardness on spindle rotation speed and tool installation angle, equipped with a cup cutter surfaced by STOODY M7-G material

Optimal cutting conditions were used to conduct the study of the influence of the tool setting angle on the surface roughness (see Figure 3c). As a result of the study, it was found that the optimal installation angle of the instrument is $\beta=10^{\circ}$. When machining with the installation angle of the instrument $\beta=10^{\circ}$, the surface roughness is $R_{a} \leq 1 \mu \mathrm{m}$ (see Figure $3 c$ ). Increasing the angle of installation tool dramatically affects the quality of processing. 
It can be seen from the graph (see Figure $3 c$ ) that when machining with an instrument installation angle $\beta=35^{\circ}$, the roughness of the machined surface is $R_{a}>10 \mu m$.

The obtained results show that the roughness and hardness of the machined surface of the hole of the part after rotational friction boring correspond to the quality of boring with boring tools equipped with hard metal plates.

\section{CONCLUSIONS}

The results of the study showed that the used cup cutter surfaces by STOODY M7-G material, is suitable for use in large holes boring. Visual inspection of the cup cutters, after the test, showed no signs of wear (scratches, chips, cracks).

When machining $30 \mathrm{HGSA}$ steel with a rotational-friction tool equipped with a cup cutter surfaced by STOODY M7-G material, it has been established that with increasing spindle speed and delivering, the quality indicators: roughness and hardness of the machined surface improve. And it also improves the quality of the process of crushing chips.

Optimal cutting conditions were established when boring a part hole made of $30 \mathrm{HGSA}$ steel using a cup cutter surfaced by STOODY M7-G material: $S=1.3 \mathrm{~mm} / \mathrm{rev}$; $n_{\text {srs }}=1250 \mathrm{rpm} ; t=1 \mathrm{~mm} ; \beta=10^{\circ}$.

As a result of the experimental studies, the following quality indicators were achieved:

- $\quad$ surface roughness within $R_{a}=10 \div 1.25 \mu \mathrm{m}$;

- $\quad$ surface hardness within HB 212-248.

The obtained results show that the roughness and hardness of the machined surface of the hole of the part after rotational friction boring correspond to the quality of boring with boring tools equipped with hard metal plates.

As a result of data processing, mathematical models were obtained for assessing the quality indicators:

- $\quad$ surface roughness $R_{a}, \mathrm{mcm}$

$Y_{1}=\left(1 /\left(8,80084 \cdot 10^{-2}+2,71133 \cdot 10^{-4} \cdot X_{1}\right)\right)+$

$\left.\left.+2,71133 \cdot 10^{-4} \cdot X_{1}\right)\right)+\left(1,70656 \cdot 10^{-1} / X_{2}\right)$

- $\quad$ hardness of the processed surface $H B, k g f / \mathrm{mm}^{2}$

$Y_{2}=1,81 \cdot 10^{3} \cdot X_{1}^{-0,383}+\left(1 /\left(7,46 \cdot 10^{-3}-\right.\right.$

$$
\left.\left.-8,11 \cdot 10^{-3} \cdot X_{2}\right)\right)-\left(156,86 / X_{2}\right)-189,29 .
$$

Preliminary calculations showed that the manufacture of the cup cutters from non-instrumental materials reduces the cost of the cutting tool by 5-7 times and the cost of the operation by 1.5-2 times.

\section{REFERENCES}

1. Nechaev, K.N. (2005). Thermofriction treatment is a promising technological direction of processing and assembly of parts. Tool and technology. SPb. Institute of Engineering. St. Petersburg: St. Petersburg Institute Publishing, No. 17-18. P.157-162.
2. Sherov, K.T., Sikhimbayev, M.R., Sherov, A.K., Donenbayev, B.S., Rakishev, A.K., Mazdubay, A.V., Musaev, M.M., Abeuova, A.M. (2017). Matematical modeling of thermofrictional milling process using ANSYS WB software. Journal of Theoretical and Applied Mechanics, Sofia, Vol. 47, No. 2. P. 24-33. https://doi.org/10.1515/jtam-2017-0008

3. Sherov, K.T., ZHetessova, G.S., Buzauova, T.M., Imasheva, K., Baizhabaginova, G.A., Ualiyev, D.S., Baibussinov, Y.A., Gurba, G.R., Sherov, A.K. (2019). Method for performing thermo-friction cutting and strengthening treatment of cylindrical surfaces of workpieces by a friction disk. Patent Number: KZ25649-A4. Primary identification number Derwent: 2019-31750G

4. Sherov, K.T., Mazdubay, A.V., Sikhimbaev, M.R., Isagulov, A.Z., Sherov, A.K., Rakishev, A.K., Mussaev, M.M., Sikhimbaeva, D.R. (2017). Thermofriction method of cutting metal blanks with cooling and the design of a circular saw. Patent of the Republic of Kazakhstan for invention No. 31934. Bull. No 6.

5. Sherov, K.T., Sikhimbayev, M.R., Donenbayev, B.S., Sagitov, A.A., Ainabekova, S.S. (2017). Experimental Research of Rotational-and-Frictional Boring of Big Holes in Large Parts. Journal of Theoretical and Applied Mechanics, Sofia, Vol. 47, No. 4. P.23-36. https://doi.org/10.1515/jtam-2017-0018

6. Khodzhibergenov, D.T., Sherov, K.T., Esirkepov, A. (2019). Drilling method and construction of a combined drill-mill bit / Russian Engineering Research. Vol. 39. No 8. pp 665-668. Allerton Press, Inc. ISSN: 1068-798X https://doi.org/10.3103/ S1068798X19080082

7. Rakishev, A.K. (2017). Research and development of a combined method of rotational-friction turning. Diss. PhD. Karaganda - P.150.

8. Nasad, T.G., Absadykov, B.N., Tusupova, S.O., Sagitov, A.A., Abdugaliyeva, G.B., Okimbayeva, A.E. (2019). Formation management in parts processing regenerated by surfacing. / News of the Academy of Sciences of the Republic of Kazakhstan, Kazakh national research technical university named after K.I. Satpayev. Series of Geology and technical sciences, №3 (435) - P.102-108. https:// doi.org/10.32014/2019.2518-170x.74

9. Adler, YU.P., Markova, E.V., Granovsky, YU.V. (1996). Planning an experiment when searching for optimal conditions. - M.: Science, P.280.

10. Usubamatov, R., Zain, Z.M., Sin, T.C., Kapaeva, S. (2016). Optimization of multi-tool machining processes with simultaneous action. Int $\mathrm{J}$ Adv Manuf Technol 82, 1227-1239. https://doi.org/10.1007/ s00170-015-6920-x 
11. Sherov, K.T., Sikhimbayev, M.R., Nasad, T.G., Absadykov, B.N., Izotova, A.S., Okimbayeva, A.E., Kuanov, I.S. (2020). The research of the steel cutting blade reliability for thermo-frictional processing / News of the National Academy of Sciences of the Republic of Kazakhstan. Series of geology and technical sciences. Volume 1, Number 439, P.122 - 130. https://doi.org/10.32014/2020.2518-170X.15

12. Ganyukov, A.A., Kadyrov, A.S., Balabekova, K.G., Kurmasheva, B.K. (2018). Tests and calculations of structural elements of temporary bridges / Roads and Bridges - Drogi i Mosty 17215 - 226. DOI: 10.7409/rabdim.018.014

13. Khodzibergenov, D.T., Ibragimova, Z.A., Khodzibergenova, U.D., Abdukarimov, A. Sherov, K.T., Esirkepov, A. (2019). Some aspects of software in cutting tools designing and testing / Russian Engineering Research. Vol. 39. No 9. pp 772-775. Allerton Press, Inc. ISSN: 1068-798X. https://doi. org/10.3103/S1068798X19090090
14. Yessirkepova, A., Sherov, K., Mikhailov, V., Buzauova, T., Mazdubay, A., \& Taskarina, A. [2020]. Research of ways of connecting reinforced bars in the production of reinforced concrete products. Journal of Applied Engineering Science, 18(3), 372-377

15. Zhunusbekova, Zh.Zh, Kadyrov, A.S. (2016). Study of digging machine flat element loading in clay solution / Journal "Naukovyi Visnyk Natsionalnoho Hirnychoho Universytetu" Volume №2 (152), P.30-33. http://nvngu.in.ua/index.php/ru/component/jdownloads/viewdownload/60/8473

16. Dudak, N., Taskarina, A., Kasenov, A., Itybaeva, G., Mussina, Z., Abishev, K., Mukanov, R. (2017). Hole Machining Based on Using an Incisive BuiltUp Reamer // International Journal of Precision Engineering and Manufacturing, Volume 18, Issue 10, Pages 1425-1432. https://doi.org/10.1007/s12541017-0170-9 